\title{
Guanidino Compounds That Are Increased in Cerebrospinal Fluid and Brain of Uremic Patients Inhibit GABA and Glycine Responses on Mouse Neurons in Cell Culture
}

\author{
Peter P. De Deyn, MD, PhD, ${ }^{* \dagger}$ and Robert L. Macdonald, MD, PhD*
}

Four guanidino compounds that have been found to be markedly increased in cerebrospinal fluid and brain tissue of uremic patients, namely, guanidine, methylguanidine, creatinine, and guanidinosuccinic acid, were applied to mouse spinal cord neurons in primary dissociated cell culture to evaluate their effects on postsynaptic responses to gammaaminobutyric acid (GABA) and glycine. Intracellular microelectrode recording techniques were used. Guanidine, methylguanidine, creatinine, and guanidinosuccinic acid reversibly and in a dose-dependent manner inhibited both GABA and glycine responses. Guanidinosuccinic acid was the most potent inhibitor of the amino acid responses, followed in decreasing potency by methylguanidine, guanidine, and creatinine. Guanidinosuccinic acid inhibited responses to GABA and glycine, at concentrations similar to those found in cerebrospinal fluid and brain tissue of patients with terminal renal insufficiency. The other guanidino compounds tested exerted their effects only at concentrations higher than those found in uremic biological fluids and tissues. The inhibitory effect of guanidine and methylguanidine on responses to GABA was additive. The effect of the guanidino compounds on GABA responses was not antagonized by coapplication of the benzodiazepine-receptor antagonist CGS 9896. The results suggest that guanidine, methylguanidine, creatinine, and guanidinosuccinic acid inhibited responses to the inhibitory neurotransmitters GABA and glycine by blocking the chloride channel. The observed action of the studied guanidino compounds might contribute to the pathogenesis of the complex neurological symptomatology encountered in uremia.

De Deyn PP, Macdonald RL. Guanidino compounds that are increased in cerebrospinal fluid and brain of uremic patients inhibit GABA and glycine responses on mouse neurons in cell culture. Ann Neurol 1990;28:627-633

Patients with renal failure develop a variety of neurological symptoms and signs. Frequent neurological complications of uremia include encephalopathy, polyneuropathy, and epilepsy [1-3]. A number of abnormal movements, including muscle fasciculations, asterixis, and myoclonus, may occur in association with varying degrees of encephalopathy in patients with acute renal failure $[1,4,5]$. The basis for the majority of the neurological complications is uncertain, and the pathophysiological mechanisms still remain to be elucidated.

Guanidino compounds have been implicated as uremic toxins since they were found to be increased in uremic biological fluids [6-10] and brain [11] and were demonstrated to induce toxic effects. Guanidinosuccinic acid is suggested to be related to the uremic bleeding diathesis $[12,13]$ and has been shown to decrease erythrocyte transketolase activity [14]. Methylguanidine could be related to the uremic polyneuropathy [15] and has been shown experimentally to induce epilepsy [16] and a syndrome similar to the uremic twitch-convulsive syndrome $[15,17]$. When injected intracisternally, methylguanidine, taurocyamine, homoarginine, creatine, and creatinine were found to have a convulsive effect in animals [18-22]. Applied on the sensorimotor cortex in rabbit, $\alpha$-keto$\delta$-guanidinovaleric acid induced electroencephalographic epileptiform discharges [23]. Furthermore; methylguanidine inhibited brain sodium-potassium ATPase $[24,25]$.

In patients with severe renal insufficiency, the levels of guanidinosuccinic acid, creatinine, guanidine, and
From the *Department of Neurology, University of Michigan Medical Center, Ann Arbor, MI, and tLaboratory of Neurochemistry, Born-Bunge Foundation, University of Antwerp, Antwerp, Belgium.
Received Sep 25, 1989, and in revised form Mar 21, 1990. Accepted for publication May 12, 1990.

Address correspondence to Dr Macdonald, University of Michigan, Neuroscience Laboratory Building, 1103 East Huron Street, Ann Arbor, MI 48104 
methylguanidine in serum as well as in cerebrospinal fluid were found to be at least ten times higher than in control subjects $[10]$. The same guanidino compounds were found to be increased from 5- to 100 -fold in different brain regions of uremic subjects [11]. The experimentally observed toxicity of these guanidino compounds might contribute to the neurological symptomatology presenting in uremia. A reduction in gamma-aminobutyric acid (GABA)ergic inhibition in the central nervous system has been suggested to be a cause of epilepsy [26-29]. A series of convulsants have been shown to inhibit responses to iontophoretically applied GABA on mammalian spinal cord neurons grown in cell culture $[30,31]$. Strychnine has been suggested to induce myoclonus, and at high concentrations convulsions, by blocking the synaptic action of the inhibitory amino acid transmitter glycine (GLY) [32], by interacting with the postsynaptic GLY receptor [33]. Furthermore, penicillin, known to inhibit GABA responses through an interaction with the GABA-receptor complex, induced spinal myoclonus after focal application in a spinal preparation in cat [34].

To determine the mechanisms through which guanidinosuccinic acid, creatinine, guanidine, and methylguanidine might produce seizures and myoclonus in uremia, we evaluated the effects of these guanidino compounds on responses evoked by iontophoretically applied GABA and GLY recorded from spinal cord neurons in cell culture.

\section{Materials and Methods \\ Primary Dissociated Cell Culture}

Cultures of spinal cord neurons were prepared from dissected spinal cords and attached dorsal root ganglia from 12 to 14-day-old fetal mice as described previously [35]. Experiments conformed to the policy of the American Physiology Society. The tissue was minced and then mechanically dissociated by trituration in $\mathrm{Ca}^{++}$- and $\mathrm{Mg}^{++}$-free balanced salt solution to a suspension of single cells and small clumps. The dissociated cells were suspended in culture medium $190 \%$ Eagle's minimal essential medium supplemented with $5.5 \mathrm{gm}$ of glucose and $1.5 \mathrm{gm}$ of sodium bicarbonate $\left(\mathrm{NaHCO}_{3}\right) / 1$, $5 \%$ heat-inactivated horse serum, and $5 \% \mathrm{Nu}$-Serum II [Collaborative Research, Inc.], $325 \mathrm{mOsmol}$ ) and then plated on sterile collagen-coated $35-\mathrm{mm}$ dishes. The cultures were maintained in an incubator with an atmosphere of $93 \%$ room air and $7 \%$ carbon dioxide $\left(\mathrm{CO}_{2}\right)$ at $35^{\circ} \mathrm{C}$. The bicarbonate/ $\mathrm{CO}^{2}$ buffer maintained the $\mathrm{pH}$ at 7.4 . On days 4 to 6 , 5-fluoro-2'deoxyuridine was added to the cultures to suppress the growth of rapidly dividing nonneuronal cells. Cultures were maintained for 4 to 9 weeks before electrophysiological experiments were performed.

\section{Experimental Procedures}

solutions. All recordings were made in Dulbecco's phosphate-buffered saline (DPBS) solution with a high magnesium-ion concentration after removal of growth medium.
The elevated magnesium concentration in the recording solution suppressed spontaneous synaptic and action potentials. The recording solution contained in $\mathrm{mM}$; sodium chloride $(\mathrm{NaCl}), 137$; sodium phosphate, dibasic $\left(\mathrm{Na}_{2} \mathrm{HPO}_{4}\right), 8.06$; potassium chloride $(\mathrm{KCl}), 2.68$; potassium phosphate, monobasic $\left(\mathrm{KH}_{2} \mathrm{PO}_{4}\right)$, 1.47; calcium chloride $\left(\mathrm{CaCl}_{2}\right)$, 1, magnesium chloride $\left(\mathrm{MgCl}_{2}\right), 10$; and glucose, $5.6(\mathrm{pH} \mathrm{7.4)}$. Heavy paraffin oil was applied to the surface of the bathing solution to retard evaporation. Solutions of drugs were always prepared on the day of the experiment in the following manner: guanidine hydrochloride, methylguanidine hydrochloride, creatinine, and guanidinosuccinic acid were dissolved in DPBS to form $100 \mathrm{mM}$ stock solutions. Aliquots were removed and diluted in bathing medium to obtain the applied concentrations. For the drug concentrations of 10 $\mathrm{mM}$ and $20 \mathrm{mM}$, iso-osmolar solutions were prepared by substituting sodium chloride with the respective guanidino compound. The $\mathrm{pH}$ of the solutions was 7.2 to 7.4 .

Guanidine and methylguanidine were applied at concentrations between $100 \mathrm{nM}$ and $100 \mathrm{mM}$. Creatinine concentrations ranged from $1 \mu \mathrm{M}$ to $20 \mathrm{mM}$ and guanidinosuccinic acid was tested at concentrations ranging between $10 \mu \mathrm{M}$ and $100 \mathrm{mM}$. CGS 9896, a pyrazoloquinoline previously shown to be a pure benzodiazepine-receptor antagonist, was dissolved in dimethylsulfoxide to obtain a $10 \mathrm{mM}$ stock solution. Aliquots were removed and diluted in bathing medium to obtain the applied concentration containing less than $0.1 \%$ dimethylsulfoxide.

EXPERIMENTAL APPARATUS. For experiments, the culture dish containing bathing solution was placed on a microscope fitted with phase contrast optics to facilitate micropipette placement (using micromanipulators) and to penetrate cells under direct visual control.

ELECTROPHYSIOLOGICAL RECORDINGS. Intracellular recordings were made from somata of spinal cord $(>20 \mu \mathrm{m})$ neurons using glass micropipettes $(25$ to $50 \mathrm{M} \Omega$ ) filled with 3 $\mathrm{M} \mathrm{KCl}$. Use of an active bridge circuit (Model 8100, Dagan Corporation, Minneapolis, MN) allowed simultaneous recording of membrane potential and injection of current (for steady-state polarization or periodic stimulation) using a single micropipette. The preamplifier output signal was led to a six-channel polygraph (Model 2600, Gould Instruments Inc., Cleveland, $\mathrm{OH}$ ) for continuous recording.

GABA AND GLYCINE RESPONSES. GABA (0.5 M, pH 3.4) and GLY $(0.5 \mathrm{M}, \mathrm{pH} 3.0)$ were applied iontophoretically using 500-millisecond rectangular current pulses at 5-second intervals. Tips of iontophoretic pipettes were positioned to within $2 \mu \mathrm{m}$ of neuronal somata. The use of $3 \mathrm{M} \mathrm{KCl-filled}$ micropipettes resulted in elevation of intracellular chloride concentration and a shift in the chloride equilibrium potential from about $-65 \mathrm{mV}$ to about $-20 \mathrm{mV}$. Under these conditions, an increase in chloride conductance results in an outward chloride current [36] giving depolarizing GABA and GLY responses [36, 37]. Responses of about 10 to 15 $\mathrm{mV}$ in amplitude were evoked following membrane hyperpolarization to between $80 \mathrm{mV}$ and $90 \mathrm{mV}$. Effects on GABA and GLY responses were accepted only if the re- 
sponses returned to control amplitude within 2 minutes of removal of the drug-containing micropipette.

DRUG APPLICATION. For evaluation of drug effects on GABA and GLY responses, all guanidino compounds were applied by perfusion micropipette. A blunt tipped (10- to $15-\mu \mathrm{m}$ ) micropipette, filled with the recording solution containing the guanidino compound, was positioned 15 to 30 $\mu \mathrm{m}$ from the soma of the cell under study. The open end of the perfusion micropipette was connected to a pressure regulator, set between 0.4 and 0.8 psi, by tight-fitting polyethylene tubing. Pressure pulse duration, regulated by a voltageactivated three-way valve, was 10 seconds. Under these conditions, local perfusion produced no artifacts and application of recording solution (with or without vehicle) was virtually free of effects. During study of the effect of coapplication of the guanidino compounds and the benzodiazepinereceptor antagonist CGS 9896 [38], the drugs were applied through one perfusion micropipette to avoid flow artifacts. The perfusion micropipettes were held by Leitz micromanipulators. To decrease leakage of drugs into the bathing medium, the tips of the perfusion micropipettes were kept in the oil phase between drug application trials.

\section{Drugs}

GABA and the guanidino compounds guanidine, methylguanidine, creatinine, and guanidinosuccinic acid (Fig 1) were purchased from Sigma Chemical (St. Louis, MO). CGS 9896 (2-( $p$-chlorophenyl)-2,5-dihydropyrazolo)4,3-C(quinolin-3(5H)-one) was obtained from Ciba-Geigy (Summit, NJ).

\section{Algebraic and Statistical Metbods}

At all applied concentrations, mean values and standard deviations were calculated for the effects on GABA and GLY responses. All effects were expressed as percent change from control GABA response. The statistical significance of differences between GABA and GLY responses with and without drug application was calculated using the two-tailed Student's $t$ test; a $p$ value of less than 0.05 was considered statistically significant.

\section{Results}

Direct Effects of Guanidine, Methylguanidine, Creatinine, Guanidinosuccinic Acid and CGS 9896 on GABA Responses

Application of the studied guanidino compounds at concentrations ranging from $100 \mathrm{nM}$ to $20 \mathrm{mM}$ to spinal cord neurons did not alter resting membrane potential or conductance. Guanidine and methylguanidine, applied at a concentration of $100 \mathrm{mM}$, induced a membrane depolarization of 10 to $25 \mathrm{mV}$. Application of recording solution $(\mathbf{n}=16)$ did not significantly alter GABA responses $(0.1 \pm 1.7 \%)$. Application of CGS $98961 \mu \mathrm{M}(\mathbf{n}=11)$ did not result in significant effects on GABA responses $(0.23$ $\pm 4.36 \%$ increase). Guanidine, methylguanidine, creatinine, and guanidinosuccinic acid rapidly and reversibly reduced GABA responses (Fig 2 ). The guanidino

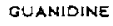

$\mathrm{NH}_{2}-\underset{\mathrm{C}}{\mathrm{C}}-\mathrm{NH}_{2}$

CREATININE<smiles>CN1CC(=O)NC1=N</smiles>

Fig 1. Structural formulas of the guanidino compounds guanidine, metbylguanidine, creatinine, and guanidinosuccinic acid.

$$
\mathrm{NH}_{2}-\underset{\text { II }}{\mathrm{C}}-\mathrm{NH}-\mathrm{CH}_{3}
$$

Janidinosuccinic acid

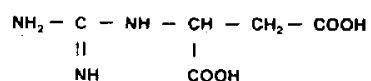

$\mathrm{NH}-\mathrm{COOH}$
PRE GUANIDINE

POSI

A

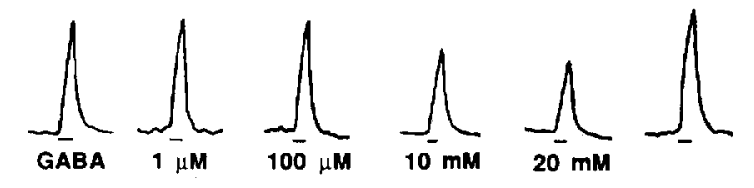

METHYLGUANIOINE

B
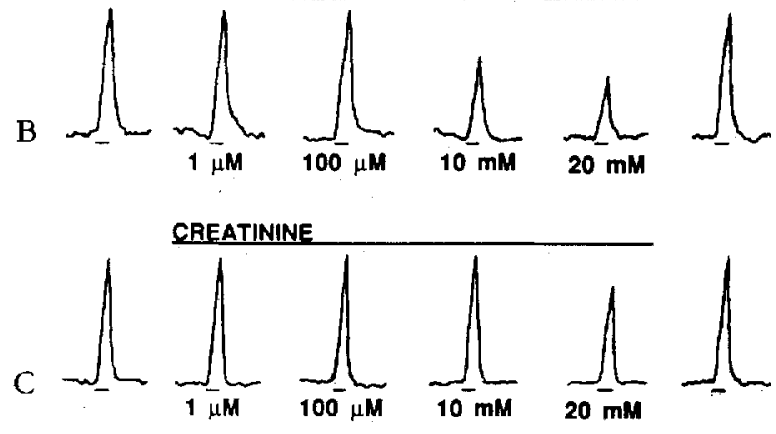

GUANIDINOSUCCINIC ACID

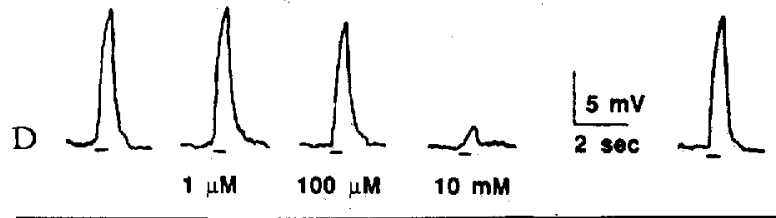

Fig 2. Reversible, concentration-dependent effects of guanidine (A), metbylguanidine (B), creatinine $(C)$, and guanidinosuccinic acid (D) on $G A B A$ responses on spinal cord neurons in primary dissociated cell culture. PRE sbows stable GABA responses before drug application. The four middle responses sbow the effect of the guanidino compound. GABA responses returned to control values (POST) within 2 minutes following removal of the guanidino compound-containing micropipette. Iontophoretic application of $G A B A$ is indicated witb a dash.

compound-induced effects were concentration dependent (Fig 3). A significant $23.9 \pm 8.45 \%$ decrease $(p$ $<0.01)(\mathbf{n}=10)$ of $\mathrm{GABA}$ responses was obtained with $10 \mathrm{mM}$ guanidine and complete inhibition was observed with $100 \mathrm{mM}(\mathrm{n}=5)$ ). A significant decrease of 34.7 $\pm 14.5 \%(p<0.001)(\mathrm{n}=16)$ was obtained 


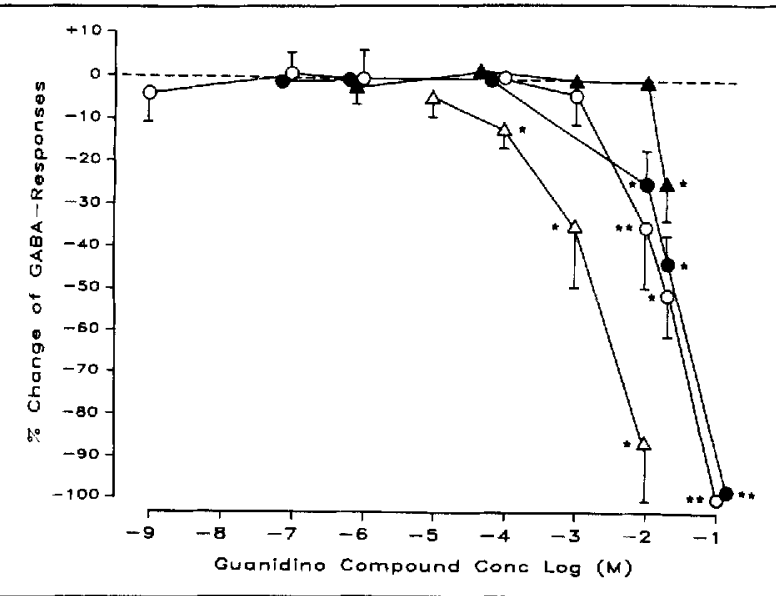

Fig 3. Concentration-dependent change of $G A B A$ responses in spinal cord neurons by guanidine (black circles), metbylguanidine (white circles), creatinine (black triangles), and guanidinosuccinic acid (white triangles). Effects are expressed in percent decrease of the original GABA response. Data shown are mean values and standard deviations. Four to sixteen cells were studied for each concentration tested. Asterisk indicates $\mathrm{p}<$ 0.01 , double asterisk, $\mathrm{p}<0.001$ from control GABA response. Guanidino compound concentrations on the abscissa are logarithm molar.

at $10 \mathrm{mM}$ methylguanidine and a total reduction of GABA responses was observed at $100 \mathrm{mM}$ methylguanidine $(n=5)$. Creatinine was devoid of any significant effect on GABA responses at concentrations up to $10 \mathrm{mM}$. At $20 \mathrm{mM}$, however, creatinine significantly reduced $\mathrm{GABA}$ responses by $23.5 \pm$ $7.55 \%(p<0.01)(\mathrm{n}=9)$. The weak inhibition of GABA responses $(3.72 \pm 4.76 \%)(\mathrm{n}=6)$ by guanidinosuccinic acid applied at $10 \mu \mathrm{M}$ was not statistically significant. However, a significant $12.1 \pm 3.69 \%$ guanidinosuccinic acid-induced decrease $(p<0.01)(\mathrm{n}=$ 6) of GABA responses was obtained at $100 \mu \mathrm{M}$ and an almost complete inhibition of $\mathrm{GABA}$ responses $(85.9 \pm 13.5 \%)(\mathrm{n}=5)$ was observed at $10 \mathrm{mM}$. Guanidinosuccinic acid was approximately ten times more potent than guanidine and methylguanidine in inhibiting GABA responses.

\section{Direct Effects of Guanidine, Metbylguanidine,}

Creatinine, and Guanidinosuccinic Acid on

Glycine Responses

Guanidine $(10 \mathrm{mM})$, methylguanidine $(10 \mathrm{mM})$, creatinine $(20 \mathrm{mM})$, and guanidinosuccinic acid $(100 \mu \mathrm{M}$ and $10 \mathrm{mM}$ ) rapidly and reversibly decreased GLY responses in a statistically significant manner $(p<$ 0.01 ) (Fig 4, Table 1). The guanidino compounds were equally potent in decreasing GLY and GABA responses.

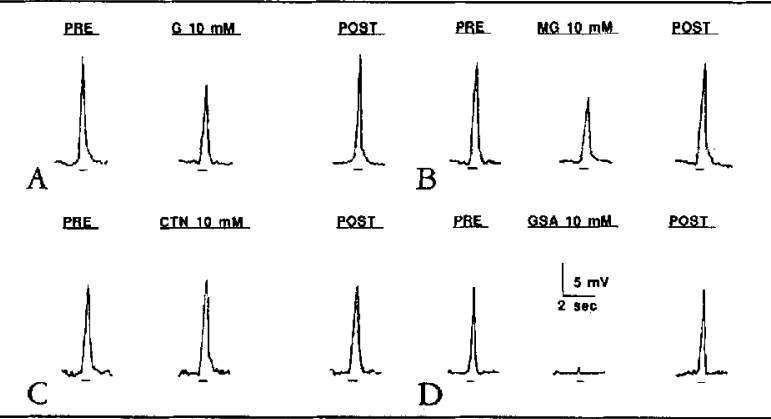

Fig 4. Reversible effects of (A) guanidine ( $G)(10 \mathrm{mM}),(B)$ methylguanidine (MG) (10 mM), (C) creatinine (CTN) (10 $m M$ ), and (D) guanidinosuccinic acid (GSA) (10 mM) on glycine responses on spinal cord neurons. PRE shows stable glycine responses before drug application. The middle response shows the effect of the miniperfused drug. Glycine responses returned to control values (POST) within 2 minutes following removal of the guanidino compound-containing micropipette. Iontophoretic application of glycine is indicated with a dash.

Table 1. Effects of Guanidine, Metbylguanidine, Creatinine, and Guanidinosuccinic Acid on Glycine (GLY) Responses on Mouse Spinal Cord Neurons

\begin{tabular}{lcll}
\hline & & $\begin{array}{l}\text { No. of } \\
\text { Cells } \\
\text { Studied }\end{array}$ & $\begin{array}{l}\text { GLY Responses } \\
\text { \% Decrease } \\
\text { (Mean } \pm \text { SD) }\end{array}$ \\
\hline Guanidine & $10 \mathrm{mM}$ & 5 & $28.1 \pm 6.31^{\mathrm{a}}$ \\
Methylguanidine & $10 \mathrm{mM}$ & 5 & $28.1 \pm 8.52^{\mathrm{a}}$ \\
Creatinine & $10 \mathrm{mM}$ & 5 & $1.86 \pm 2.68$ \\
Guanidino- & $20 \mathrm{mM}$ & 6 & $31.0 \pm 7.77^{\mathrm{a}}$ \\
$\quad$ succinic acid & $100 \mu \mathrm{mM}$ & 4 & $14.8 \pm 6.00^{\mathrm{a}}$ \\
\hline
\end{tabular}

${ }^{a} p<0.01$, from control, Student's two-tailed $t$ test.

Effects of Coapplication of Guanidine, Methylguanidine, Creatinine, and Guanidinosuccinic Acid with CGS 9896 on GABA Responses

The effects on GABA responses of guanidine (10 $\mathrm{mM})$, methylguanidine $(10 \mathrm{mM})$, creatinine $(20 \mathrm{mM})$, and guanidinosuccinic acid $(10 \mathrm{mM})$ alone or in combination with CGS $9896(1 \mu \mathrm{M})$, a pure benzodiazepinereceptor antagonist, were not significantly different (Table 2).

\section{Additive Effects of Guanidine and Metbylguanidine on GABA Responses}

Coapplication of methylguanidine $(10 \mathrm{mM})$ and guanidine $(10 \mathrm{mM})$ resulted in a significantly larger inhibition of GABA responses than when either of these compounds were applied alone at $10 \mathrm{mM}$. Whereas methylguanidine $(10 \mathrm{mM})$ reduced GABA responses $25.7 \pm 7.37 \%(\mathbf{n}=3)$ and guanidine $(10 \mathrm{mM})$ reduced GABA responses $23.3 \pm 4.1 \%(\mathrm{n}=3)$, their 


\begin{tabular}{lll}
\hline & & $\begin{array}{l}\text { GABA Responses } \\
\text { \% Decrease } \\
\text { (Mean } \pm \text { SD) }\end{array}$ \\
\hline CGS $9896(1 \mu \mathrm{M})$ & No. of Cells Studied & $0.23 \pm 4.36$ \\
Guanidine $(10 \mathrm{mM})$ & 11 & $24.9 \pm 0.75$ \\
Guanidine $(10 \mathrm{mM})+$ CGS $9896(1 \mu \mathrm{M})$ & 3 & $24.3 \pm 9.10$ \\
Methylguanidine $(10 \mathrm{mM})$ & 3 & $28.5 \pm 3.69$ \\
Methylguanidine $(10 \mathrm{mM})+$ CGS $9896(1 \mu \mathrm{M})$ & 5 & $32.2 \pm 6.74$ \\
Creatinine $(20 \mathrm{mM})$ & 5 & $21.0 \pm 5.81$ \\
Creatinine $(20 \mathrm{mM})+$ CGS $9896(1 \mu \mathrm{M})$ & 3 & $21.1 \pm 7.39$ \\
Guanidinosuccinic acid $(10 \mathrm{mM})$ & 3 & $94.7 \pm 9.12$ \\
Guanidinosuccinic acid $(10 \mathrm{mM})+$ CGS $9896(1 \mu \mathrm{M})$ & 3 & $93.3 \pm 11.5$ \\
\hline
\end{tabular}

${ }^{a}$ Vertical lines indicate paired samples. No significant differences were found (Student's $t$ test for paired samples).

coapplication resulted in a $39.7 \pm 7.93 \%(\mathrm{n}=3)$ decrease of GABA responses.

\section{Discussion}

A variety of convulsants have been shown previously to inhibit GABAergic inhibition [37, 39-41] through interaction with the postsynaptic GABA-receptor complex consisting of a functionally coupled benzodiazepine receptor, GABA receptor, and chloride channel $[42,43]$. Several convulsants reduced responses to iontophoretically applied GABA on mouse neurons grown in cell culture. DMCM, a convulsant betacarboline, and CGS 8216, a pyrazolo-quinoline with proconvulsant effect, inhibited GABA responses [38, $41,44,45]$ through an interaction with the benzodiazepine receptor. Moreover, the convulsants bicuculline, picrotoxin, and pentylenetetrazole were previously reported to selectively antagonize GABAmediated postsynaptic inhibition in cultured mammalian neurons $[37,39,41,45]$. Penicillin, a convulsant that is known to induce myoclonus after intravenous administration in humans [46] and focal application in cat, [34] also antagonized GABA responses on mouse neurons [39]. Strychnine, inducing myoclonus at low doses and convulsions at higher concentrations, has been shown previously to be a GLY-receptor antagonist [33].

In this study, we investigated the effects of four guanidino compounds, which were found to be increased in cerebrospinal fluid and brain of uremic patients $[10]$, on responses to the iontophoretically applied inhibitory neurotransmitters GABA and GLY on mouse neurons in primary dissociated cell culture. The guanidino compounds were guanidine, methylguanidine, creatinine, and guanidinosuccinic acid.

Guanidine, methylguanidine, creatinine, and guanidinosuccinic acid inhibited both GABA and GLY re- sponses on mouse spinal cord neurons in culture in a concentration-dependent manner. Guanidinosuccinic acid was the most potent compound, followed by methylguanidine, guanidine, and creatinine. Guanidinosuccinic acid inhibited GABA and GLY responses at concentrations similar to those found in cerebrospinal fluid (up to $32 \mu \mathrm{M}$ ) and brain tissue (up to 21 $\mathrm{nmol} / \mathrm{gm}$ of tissue) of patients with terminal renal insufficiency. The studied guanidino compounds did not reduce $G A B A$ responses through an interaction with the benzodiazepine receptor. Indeed, CGS 9896, a pyrazoloquinoline and pure benzodiazepine-receptor antagonist [38], did not antagonize the guanidino compound-induced inhibition of GABA responses. Earlier studies on cultured neurons demonstrated that the inhibitory neurotransmitters GABA and GLY act through different receptors on the membrane surface $[30,47,48]$. Moreover, activation of chloride conductance has been demonstrated to underlie the GABAand GLY-receptor-coupled events [49]. Since GABA and GLY exert their inhibitory effects by activation of chloride conductance through interaction with different receptors, our observations suggest that guanidine, methylguanidine, and guanidinosuccinic acid, shown here not to be benzodiazepine-receptor ligands, inhibit inhibitory amino acid-responses by blocking chloride channels.

Structure-activity relationships cannot be established from the data presented in this report. Creatinine, the anhydrized form of creatine, was the least potent in decreasing responses to GABA and GLY, whereas the monosubstituted guanidino compounds guanidinosuccinic acid and methylguanidine were more potent than guanidine. Previous reports demonstrated that the potency of $\mathrm{N}$-alkyl-guanidino compounds in blocking ionic channels of the motor end-plate membrane was a function of the length of the alkyl side chain [50]. It was suggested that the blocking potency, enhanced by 
lengthening the side chain, might be related to the increase in side chain hydrophobicity.

The observed inhibitory effects of guanidine, methylguanidine, creatinine, and guanidinosuccinic acid on inhibitory neurotransmitter responses might have pathophysiological implications in uremia. Indeed, guanidinosuccinic acid displayed significant effects on GABA and GLY responses at concentrations similar to those found in cerebrospinal fluid and brain tissue of uremic patients $[10,11]$. Moreover, guanidine, methylguanidine, and creatinine, which reduced GABA and GLY responses only at concentrations higher than those hitherto found in cerebrospinal fluid of uremic patients, might have, perhaps in combination with still other toxins, additive effects. The additive inhibitory effect of guanidine and methylguanidine on responses to GABA has been demonstrated in this report. A summative effect has also been shown for creatinine, creatine, guanidinoaceric acid, and guanidine in an experimental paradigm testing in vitro autohemolysis [24]. Earlier reports demonstrated methylguanidine [16] to be more potent than creatinine [20] in inducing seizures in rabbit after intracisternal administration. This is in agreement with the higher potency of methylguanidine in decreasing responses to inhibitory neurotransmitters as illustrated in this report. The in vivo epileptogenicity of guanidine and guanidinosuccinic acid has not been demonstrated or disproved as yet.

In addition to reducing GABA and GLY responses, other postsynaptic and presynaptic effects have been shown for guanidino compounds in the peripheral as well as in the central nervous system. Guanidine has been shown to increase transmitter release at the frog, rat, and crayfish neuromuscular junctions [51-54] and in the guinea pig olfactory cortex [55]. In addition, methylguanidine inhibited responses to acetylcholine in frog sartorious muscle $[50,52]$ and guanidine was found to have a dual effect on cat spinal monosynaptic reflex transmission (inhibiting at low doses and enhancing at high doses) [56]. These electrophysiological effects and reduction of GABA and GLY responses by the guanidino compounds might contribute to the central and peripheral nervous system symptomatology presenting in uremia. Moreover, methylguanidine has been shown to inhibit brain sodium-potassium ATPase, an effect which could also contribute to its epileptogenic activity [25].

In conclusion, guanidine, methylguanidine, creatinine, and guanidinosuccinic acid, found to be increased in cerebrospinal fluid and brain of uremic patients, inhibited responses to the inhibitory neurotransmitters GABA and GLY on mouse neurons in cell culture. Guanidinosuccinic acid inhibited GABA and GLY responses at concentrations similar to those previously found in cerebrospinal fluid and brain of uremic patients. The underlying mechanism is suggested to be the blocking of the chloride channel. This effect, alone or in combination with other effects exerted by these compounds or other toxins, might underlie the pathogenesis of the myoclonus, epilepsy, and encephalopathy presenting in uremia.

Financial support was provided by US Public Health Service grant NS 19613, the North Atlantic Treaty Organization, and the BornBunge Foundation.

The authors wish to thank Ms Nancy Fox for technical assistance.

\section{References}

1. Tyler HR. Neurological aspects of uremia: an overview. Kidney Int 1975; (Suppl):S188-193

2. Reese GN, Appel SH. Neurologic complications of renal failure. Semin Nephrol 1981;1:137-150

3. Fraser CL, Arieff AI. Nervous system complications in uremia. Ann Intern Med 1988;109:143-153

4. Stark RJ. Reversible myoclonus with uraemia. Br Med J 1981;282:1119-1120

5. Chadwick D, French AT. Uraemic myoclonus: an example of reticular reflex myoclonus. J Neurol Neurosurg Psychiatry 1979;42:52-55

6. Cohen BD. Guanidinosuccinic acid in uremia. Arch Intern Med 1970;126:846-850

7. Giovannetti S, Balestri PL, Barsotti G. Methylguanidine in uremia. Arch Intern Med 1973;131:709-713

8. De Deyn PP, Marescau B, Lornoy W, et al. Guanidino compounds in uraemic dialyzed parients. Clin Chim Acta 1986; 157:143-150

9. De Deyn PP, Marescau B, Lornoy W, et al. Serum guanidino compound levels and the influence of a single hemodialysis in uremic patients undergoing maintenance hemodialysis. Nephron 1987;45:291-295

10. De Deyn PP, Marescau B, Cuykens JJ, et al. Guanidino compounds in serum and cerebrospinal fluid of non-dialyzed patients with renal insufficiency. Clin Chim Acta 1987;167:81-88

11. De Deyn PP. Analytical studies and pathophysiological importance of guanidino compounds in uremia and hyperargininemia. Thesis submitted to obtain the degree of "Geaggregeerde van het Hoger Onderwijs," University of Antwerp, Universitaire Instelling Antwerpen, 1989.

12. Stein IM, Cohen BD, Horowitz HI. Guanidinosuccinic acid: the "X" factor in uremic bleeding? Clin Res 1968;16:397

13. Horowitz HI, Cohen BD, Martinez P, Papayouanou MF. Defective ADP-induced platelet factor 3 activation in uremia Blood 1967;30:331-340

14. Lonergan ET, Semar M, Terzel RB, et al. Erythrocyte transketolase activity in dialyzed patients. A reversible metabolic lesion of uremia. N Engl J Med 1971;284:1399-1403

15. Giovannetti S, Biagini M, Balestri PL, et al. Uremia-like syndrome in dogs chronically intoxicated with methylguanidine and creatinine. Clin Sci 1969;36:445-452

16. Matsumoto $M$, Mori $A$. Convulsive activity of methylguanidine in cat and rabbits. IRCS Med Sci 1976;4:65

17. Minot A, Dodd K. Guanidino intoxication. J Dis Child 1933; 46:522-530

18. Mori A. Biochemistry and neurotoxicology of guanidino compounds. History and recent advances. Pavlov J Biol Sci 1987; 22:85-94

19. Jinnai D, Mori A, Mukawa J, et al. Biochemical and physiologi- 
cal studies on guanidino compounds induced convulsions. Jpn J Brain Physiol 1969;106:3668-3673

20. Jinnai D, Sawai A, Mori A. $\gamma$-Guanidinobutyric acid as a convulsive substance. Nature 1966;212:617

21. Mori A, Katayama Y, Yokoi I, Matsumato M. Inhibition of taurocyamine (guanidinotaurine)-induced seizures by taurine. In: Baskin SI, Kocsis JJ, eds. The action of taurine on excitable tissues. New York: Schaffern, Spectrum Publications, 1981:4148

22. Yokoi I, Toma J, Mori A. The effect of homoarginine on the EEG of rats. Neurochem Pathol 1984;2:295-300

23. Marescau B, Hiramatsu M, Mori A. $\alpha$-Keto- $\delta$-guanidinovaleric acid-induced electroencephalographic epileptiform discharges in rabbits. Neurochem Pathol 1983;1:203-209

24. Giovannetti S, Cioni L, Balestri PL, Biagini M. Evidence that guanidines and some related compounds cause hemolysis in chronic uremia. Clin Sci 1968;34:141-148

25. Minkoff L, Gaertner G, Darab M, et al. Inhibition of brain sodium-potassium ATPase in uremic rats. J Lab Clin Med 1972;80:71-78

26. Lloyd KG, Munari C, Bossi L, et al. Biochemical evidence for the alterations of GABA-mediated synapric transmission in pathological brain tissue (stereo EEG or morphological definition) from epileptic patients. In: Morselli PL, Lloyd KG, Loscher W, eds. Neurotransmitters, seizures and epilepsy. New York: Raven Press, 1981:325-338

27. Meldrum B. Convulsant drugs, anticonvulsants and GABAmediated neuronal inhibition. In: Krogsgaard-Larsen P, ScheelKruger J, Kofod $\mathrm{H}$, eds. Neurotransmitters. Copenhagen: Munksgaard, 1979:390-405

28. Olsen RW. The GABA postsynaptic membrane receptorionophore complex: site of action of convulsant and anticonvulsant drugs. Mol Cell Biochem 1981;39:261-279

29. Roberts E. Epilepsy and antiepileptic drugs: a speculative synthesis. In: Glaser GH, Penry JK, Woodbury HD, eds. Antiepileptic drugs: mechanisms of action. New York: Raven Press, 1980:667-713

30. Macdonald RL, Barker JL. Specific antagonism of GABAmediated postsynaptic inhibition in cultured mammalian spinal cord neurons: a common mode of convulsant action. Neurology 1978:28:325-330

31. De Deyn PP, Marescau B, Macdonald RL. Effects of $\alpha$-keto- $\delta$ guanidinovaleric acid on inhibitory amino acid responses on mouse neurons in cell culture. Brain Res 1988;449:54-60

32. Curtis DR, Johnston GAR. Amino acid transmitters in the mammalian central nervous system. Ergeb Physiol 1974;69:97188

33. Young $A B$, Snyder $S H$. Strychnine binding in rat spinal cord membranes associated with the synaptic glycine receptor: cooperativity of glycine interactions. Mol Pharmacol 1974;10: 790-809

34. Kao LI, Grill WE. Penicillin-induced segmental myoclonus. Arch Neurol 1972;26:156-161

35. Ransom BR, Neale E, Henkart M, et al. Mouse spinal cord in cell culture. I. Morphology and intrinsic neuronal electrophysiologic properties. J Neurophysiol 1977;40:1132-1150

36. Curtis DR, Hösli L, Johnston GAR, Johnston IH. The hyperpolarization of spinal motoneurons by glycine and related amino acids. Exp Brain Res 1968;5:235-258

37. Nowak LM, Young AB, Macdonald RL. GABA and bicuculline action on mouse spinal cord and cortical neurons in cell culture. Brain Res 1982;244:155-164

38. De Deyn PP, Macdonald RL. CGS 9896 and ZK 91296, but not CGS 8216 and Ro 15-1788, are pure benzodiazepine receptor antagonists on mouse neurons in cell culture. J Pharmacol Exp Ther 1987;242:48-55

39. Macdonald RL, Barker JL. Pentylenetetrazol and penicillin are selective antagonists of GABA-mediated postsynaptic inhibition in cultured mammalian neurones. Nature 1977;267:720-721

40. Schofield CN. Leptazol antagonizes the postsynaptic actions of $\gamma$-aminobutyric acid. Br J Pharmacol 1978;63:495-502

41. Skerritt JH, Macdonald $\mathrm{RL}$. Benzodiazepine receptor ligand actions on GABA-responses: $\beta$ carbolines, purines. Eur J Pharmacol 1984;101:135-141

42. Tallman JF, Paul SM, Skolnick P, Gallager DW. Receptors of the age of anxiety: pharmacology of the benzodiazepines. Science 1980;207:274-281

43. Schofield PR, Darlison MG, Fujita N, et al. Sequence and functional expression of the $G A B A_{A}$ receptor shows a ligand-gated receptor super-family. Nacure 1987;328:221-227

44. Jensen MS, Lambert JDC. The interaction of the $\beta$-carboline derivarive DMCM with inhibitory amino acid responses on cultured mouse neurons. Neurosci Lett 1983;40:175-179

45. De Deyn PP, Macdonald RL. Effects of antiepileptic drugs on GABA-responses and on PTZ- and DMCM-irsluced reduction of GABA-responses on mouse neurons in cell culture. Epilepsia 1989;30:17-25

46. Sackellaris JC, Smith DB. Myoclonus with electrocerebral silence in a patient receiving penicillin. Arch Neurol 1979;36: $857-858$

47. Nelson PG, Ransom BR, Henkart M, Bullock PN. Mouse spinal cord in cell culture. IV. Modulation of inhibitory synaptic function. J Neurophysiol 1977;40:1178-1187

48. Ransom BR, Bullock PN, Nelson PG. Mouse spinal cord in cell culture. III. Neuronal chemosensitivity and its relationship to synaptic activity. J Neurophysiol 1977;40:1163-1177

49. Barker JL, Ransom BR. Amino acid pharmacology of mammalian central neurons grown in tissue culture. J Physiol (Lond) 1978;280:331-354

50. Farley JM, Yeh JZ, Watanabe S, Narahashi T. Endplate channel block by guanidine derivatives. J Gen Physiol 1981;77: $273-293$

51. Otsuka M, Endo M. The effects of guanidine on neuromuscular transmission. J Pharmacol Exp Ther 1960;128:273-282

52. Farley JM, Glavinovic MI, Watanabe S, Natahashi T. Stimulation of transmitter release by guanidine derivatives. Neuroscience 1979;4:1511-1519

53. Teräväinen $\mathbf{H}$, Larsen A. Effect of guanidine on quantal release of acetylcholine in the mammalian myoneuronal junction. Exp Neurol 1975;48:601-609

54. Lundh $\mathrm{H}$, Leander S, Thesleff S. Antagonism of the paralysis produced by botulinum toxin in the rat. The effects of tetraethylammonium, guanidine and 4-aminopyridine. J Neurol Sci $1977 ; 32: 29-43$

55. Galvan M, Gafe P, ten Bruggencate G. Facilitatory actions of guanidine on synaptic transmission in mammalian brain slices. Exp Neurol 1980;67:234-246

56. Hall ED, Fenstermaker RA. Actions of guanidine hydrochloride on cat spinal monosynaptic reflex transmission. Neurology $1983 ; 22: 697-702$ 